Association for Information Systems AIS Electronic Library (AISeL)

ECIS 2009 Proceedings

European Conference on Information Systems

$1-1-2009$

\title{
Knowledge clusters: Dealing with a multilevel phenomenon
}

Mamata Bhandar

U21 Global, mbhandar@u21global.edu.sg

Shan L. Pan

National University of Singapore, pansl@comp.nus.edu.sg

Bernard C. Y. Tan

National University of Singapore, btan@comp.nus.edu.sg

Follow this and additional works at: http://aisel.aisnet.org/ecis2009

\section{Recommended Citation}

Bhandar, Mamata; Pan, Shan L.; and Tan, Bernard C. Y., "Knowledge clusters: Dealing with a multilevel phenomenon" (2009). ECIS 2009 Proceedings. 338.

http://aisel.aisnet.org/ecis2009/338

This material is brought to you by the European Conference on Information Systems (ECIS) at AIS Electronic Library (AISeL). It has been accepted for inclusion in ECIS 2009 Proceedings by an authorized administrator of AIS Electronic Library (AISeL). For more information, please contact elibrary@aisnet.org. 
Association for Information Systems AIS Electronic Library (AISeL)

ECIS 2009 Proceedings

European Conference on Information Systems

1-1-2009

\section{Knowledge clusters: Dealing with a multilevel phenomenon}

Mamata Bhandar

U21Global, mbhandar@u21global.edu.sg

Shan L. Pan

National University of Singapore, pansl@comp.nus.edu.sg

Bernard C. Y. Tan

National University of Singapore, btan@comp.nus.edu.sg

Follow this and additional works at: http://aisel.aisnet.org/ecis2009

\section{Recommended Citation}

Bhandar, Mamata; Pan, Shan L.; and Tan, Bernard C. Y., "Knowledge clusters: Dealing with a multilevel phenomenon" (2009). ECIS 2009 Proceedings. Paper 338.

http://aisel.aisnet.org/ecis2009/338

This material is brought to you by the European Conference on Information Systems (ECIS) at AIS Electronic Library (AISeL). It has been accepted for inclusion in ECIS 2009 Proceedings by an authorized administrator of AIS Electronic Library (AISeL). For more information, please contact elibrary@aisnet.org. 


\title{
KNOWLEDGE CLUSTERS: DEALING WITH A MULTILEVEL PHENOMENON
}

\author{
Bhandar, Mamata, U21 Global, 5 Shenton Way, \#01-01, UIC Building, Singapore 068808. \\ mbhandar@u21global.edu.sg \\ Pan, S-L, National University of Singapore, 3 Science Drive 2, Singapore 117543. \\ pans1@comp.nus.edu.sg
}

Tan, Bernard, National University of Singapore, 3 Science Drive 2, Singapore 117543. btan@comp.nus.edu.sg

\begin{abstract}
The central idea of this paper is to comprehend knowledge integration in inter-organizational IS projects through a knowledge cluster view of inter-organizational IS projects. The proliferation of such projects combined with the complexity of managing them, motivated this study. The study is based on a single case study which involves four organizations collaborating on a project. Findings suggest that knowledge integration in inter-organizational projects occurs through knowledge clusters and involves the interaction of complementary specialized knowledge bases within a structure and influenced by the clusters' perceptions towards the project. Implications of the findings and future research opportunities are discussed.
\end{abstract}

Keywords: Knowledge cluster, knowledge integration, multi-level analysis, inter-organizational projects

\section{INTRODUCTION}

Inter-organizational arrangements for mutual benefits in the form of partnerships, alliances and joint ventures are very common. Such arrangements take place for several reasons including resource efficiency, resource acquisition, and skill enhancement (Simatupang et al 2002). Of the different types of inter-organizational arrangements, this study focuses on inter-organizational IS projects, an organizational form in which multiple organizations collaborate on an IS project for a specific period of time and that involve a client-vendor relationship. The simplest of such projects may involve one client and one vendor, but the more complex may have multiple clients or/and multiple vendors. With companies increasingly outsourcing all or some of their IS activities (Lacity and Hirschheim 1993), including IS development, it is very common indeed to see IS projects that involve multiple organizations.

Development of Information systems is a complex, intensive, and dynamic activity that requires close cooperation and coordination among diverse stakeholders who house the knowledge required for the execution of the project. In inter-organizational IS projects, knowledge required for the project is situated in the diverse stakeholders that belong to different functional groups (departments, users, management, IT etc) and are part of different organizations. Typically for a project some representatives from each of these departments/ functional groups/stakeholders, referred to as knowledge clusters in this paper, are involved in the project. Specifically, knowledge clusters in this study refers to a group that possesses certain specialized knowledge essential for the project (e.g. users, IT department representatives) and that is governed by similar rules and boundaries (e.g. 
departments) and hence the members share similar perceptions towards the project. This definition of knowledge clusters is similar to that adopted by Yayavaram and Ahuja(2008), although they have not explicitly defined the term and they base their definition on technologies. Other studies that have defined the term are in the context of industrial clusters, as cluster of firms, a more macro level view than our consideration. Knowledge from multiple knowledge clusters in each collaborating organization can be highly differentiated and specialized and therefore has to be integrated for the project.

Knowledge integration, in this context is conceptualized as the process through which disparate, specialized knowledge located in multiple knowledge clusters across organizations is combined, applied and assimilated. For instance, in an IS project, the users from the client organization communicate system requirements to the vendor's IT consultants who use their software expertise and knowledge from the users to build the system. Users then assimilate the system by making necessary changes to their work practices (Faraj and Sproull 2000; Huang et al 2001). Knowledge integration is essential since if knowledge from a particular cluster is missing or is not integrated, for example, lack of user participation and hence unclear requirements, the project outcome may suffer. The several constraints like time, budget, specifications require knowledge integration in an inter-organizational IS project to be effective, i.e. knowledge for the project has to integrated within the stated constraints.

Managing the knowledge integration process between the organizations in a project is a crucial task (Walz et al 1993) and is a challenge not only because knowledge is often dispersed, differentiated and embedded (e.g. Tsoukas 1996) in various knowledge clusters but also because the clusters have their own agendas within organizations that are intrinsically different, that may possess diverse competencies (Pisano 1994) and conflicting interests. The fact that many of the systems are developed under extreme time constraints and often with the help of external consultants exacerbate the challenges associated with combining diverse forms of expertise on particular projects (Levina 2005). Client-vendor relationships in outsourced IS development projects have always been presumed to be adversarial (e.g. Chowdhry and Sabherwal 2003) and the associated factors, along with the difficulties in obtaining quick feedback, meeting frequently, and building interpersonal relationships, make their management an arduous task.

How then is knowledge across multiple knowledge clusters from multiple diverse organizations integrated for effective knowledge integration in inter-organizational IS projects? To address this question and increase our understanding of this complex phenomenon in a challenging environment an empirical study of an inter-organizational IS project is conducted. Related literature is reviewed and knowledge cluster concept cluster explained in the following section.

\section{LITERATURE REVIEW}

\subsection{Knowledge and Knowledge clusters}

This study bases itself on the view that knowledge exists in the individual and the collective (Nonaka 1994) and both include the tacit and explicit dimensions of knowledge as suggested by the early works of Polanyi (1966). Individuals in their clusters are assumed to be the prime vehicle of knowledge delivery to the project irrespective of its nature and location. The notion of collective knowledge is important because Collective knowledge can also refer to knowledge situated in various departments, groups or teams. The representatives of certain departments, groups, teams are referred to as knowledge clusters in this study and they house the different types and forms of specialized knowledge (e.g. process knowledge, requirements) required for the project. The concept of knowledge cluster is represented in figure 2.1. 


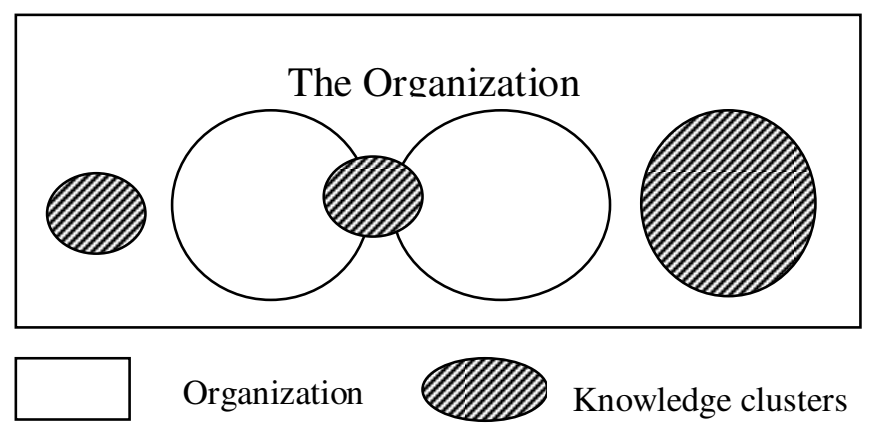

$\bigcirc$ Knowledge bases; departments, functional groups

Figure 1: The Knowledge Cluster

Each knowledge cluster groups representatives from a certain knowledge area that will be involved in the project. This group can include some representatives from one knowledge base, more than one knowledge base or the entire knowledge base. For instance, knowledge cluster can be a few members from a certain department (e.g. users), representatives from two or more departments (e.g. multiple user departments) or the entire department (e.g. when the user department is small and everybody's knowledge is required for the project). These three possibilities are shown in figure 1 above.

Yayavaram and Ahuja(2008) used the term knowledge cluster more in the context of their definition of a knowledge structure with respect to a firm's technical knowledge. According to them a knowledge cluster can be a group of people, but that need not always be the case and some times it can be a group of related technologies. Although the usage of the term is similar the distinction in our adoption of the concept is mainly due to the context. Knowledge clusters in this paper are a group of people, encompassing individuals' knowledge, the collective knowledge and embedded routines and practices thus including related technical knowledge as well. In identifying clusters for the current study, groups that were to contribute the same type of functional knowledge were considered; i.e most of the identified clusters belonged to different functional areas such as users, IT, management, or different vendor organizations with their specialized knowledge. The specialized knowledge of the clusters also provided a sense of the cluster's role in the project, attitude, perception hence knowledge integration behaviour of the cluster towards the project.

\subsection{Knowledge Integration and Inter-organizational IS Projects}

Scholars have proposed different definitions of knowledge integration (table 2). For this study the knowledge integration as proposed by Bhandar et al (2007) is adopted since it incorporates a process view and is easily applicable to an inter-organizational context. Based on their view, knowledge integration for this study is viewed as the process through which relevant knowledge from different clusters is combined, applied and assimilated for the goal of the project. This view implies that knowledge integration is achieved through several activities starting from project negotiations to the post-implementation stages and is also influenced by certain antecedent conditions like reason for initiating the project. It also suggests that knowledge integration process requires the knowledge clusters to be involved in the process to contribute, apply and assimilate knowledge. Okhyusen and Eisenhardt (2002) add that knowledge integration is not about assembling discrete pieces of knowledge, but depends on how members know and integrate their individually held knowledge and so is influenced by the surrounding environment. 


\begin{tabular}{|l|l|}
\hline \multicolumn{1}{|c|}{ Definition } & \multicolumn{1}{|c|}{ Author/s } \\
\hline Application of knowledge & Grant 1996 \\
\hline $\begin{array}{l}\text { Synthesis of knowledge bases } \\
\text { Process view: an ongoing collective processes of constructing, articulating, and } \\
\text { redefining shared beliefs through social interaction of organizational members }\end{array}$ & Huang et al 2001 \\
\hline $\begin{array}{l}\text { Distinguish between knowledge integration process and knowledge integration per se. } \\
\text { The process involves the actions of group members by which they share their } \\
\text { individual knowledge within the group and combine it to create new knowledge. By } \\
\text { contrast, knowledge integration is the outcome of this process, consisting of both the } \\
\text { shared knowledge of individuals and the combined knowledge that emerges from their } \\
\text { interactions }\end{array}$ & Eisenhardt (2002) \\
\hline $\begin{array}{l}\text { Defines knowledge integration specifically in the context of IS projects as the process Tiwana (2004) } \\
\text { of embodying business application domain knowledge with technical knowledge in the } \\
\text { design of the software. }\end{array}$ & \\
\hline $\begin{array}{l}\text { Process view- process through which relevant knowledge is combined, applied and Bhandar et al(2007) } \\
\text { assimilated }\end{array}$ & \\
\hline
\end{tabular}

\section{Table 1: Knowledge integration views and definitions}

The process of knowledge integration in inter-organizational IS projects as described involves ongoing interaction between the clusters to contribute knowledge and share common experiences to redefine shared beliefs through social interaction(Huang et al 2001) thus entailing that the clusters have a motivation to be part of the project. For instance, top management may need the system but the user department may not. This can affect the users' assimilation of the system hence their participation in the knowledge integration process. Okhyusen and Eisenhardt(2002) highlight the importance of structures to improve interactions among group members for knowledge integration and Van Den Bosch et al (1999) and Grant(1996) suggested the importance of the ability of the firm for knowledge integration. Clusters need to possess the ability to comprehend the ideas and perspectives being exchanged so as to contribute knowledge to the project and reinforce the common knowledge base, i.e. the overlap of knowledge that exists between the network members (Demsetz, 1991; Grant, 1996).

Knowledge integration in inter-organizational IS projects is not easy given it involves the integration of knowledge spanning cross functional capabilities (Carlile and Rebentisch 2003) which is more complicated compared to integrating one kind of knowledge across individuals or groups(Grant 1996), notwithstanding the inherent characteristics of knowledge that can make its integration difficult. The common knowledge that exists in an inter-organizational set-up is modest and the fact that knowledge in each organization exists in multiple entities further adds to the challenge. Additionally, these projects involve managing knowledge clusters from different organizations. The clusters are affected by the inter-organizational dynamics such as distinct competencies (Pisano 1994) and conflicting interests that have to be overcome before their knowledge can be integrated (Pan et al 2001). Conflicts inherent in a client-vendor relationship (Lacity and Hirschheim 1993) although healthy from the perspective of the organization can affect the behavior of knowledge clusters towards knowledge integration. So how then is knowledge integrated in inter-organizational IS projects? To address this question and understand this complex phenomenon in a challenging set-up, an empirical study of a four organization project is undertaken. The methodology followed for the study is discussed next.

\section{METHODOLOGY}

Qualitative research method was adopted for this study since it allows an emphasis on processes and meanings (Denzin and Lincoln 1994) essential for this study investigating a knowledge integration process. The case study method was deemed appropriate for data collection since the phenomenon of knowledge integration is closely intertwined with the context of the inter-organizational project (Yin 2003). The study also required informants to reveal sensitive data that required comprehension of the context (e.g. to interpret the quotes in light of their relationships) which was possible through long and 
informal interviews. This project was chosen for the study based on three criteria: the project was recently completed to ensure that participants could recall events, permission to study the project was granted by the top management so as to allow access to rich data, and it provided a right context for the study, an inter-organizational project with four organizations and client-vendor relationship.

The main source of data was face-to-face interviews conducted with representatives of each organization involved in the project at different hierarchies (top management, middle management, team members and users). Questions were asked to understand the motivations/expectations/views of each organization/cluster for the project, their account of how the project progressed, the conflicts and resolution of conflicts. Secondary data was collected from organizational websites (e.g. organizational background), articles, and third parties (employees of the companies not involved in the project). The multiple sources provided for triangulation (Stake 1994) of evidence, ensured that facts stated by one cluster could be verified by the other and also provided multiple perspectives on issues.

Data analysis was done in iteration with data collection (Myers 1997; Walsham 2006). Initially analysis was conducted at an organizational level, through which the behaviour of some members could be explained. The researcher then adopted a cluster level analysis, since they saw behaviour of members could be better explained from the cluster they area associated with rather than the organization. Data collected was transcribed in consideration with recording media for qualitative studies (Walsham 1995, 2006). Themes were identified using open-coding (Strauss and Corbin 1990) that influenced the organizations knowledge integration behavior throughout the project. For instance, 'prior experience' and 'lack of motivation' were identified as themes that influenced 'requirement gathering' since they affected time taken/outcome for that activity. Interesting comments, surprising revelations, special notes/observations made during the site visits or interviews were also considered. For example, highly sceptical tone, formal atmosphere, and interviewees being very guarded in disclosing facts were all noted. The case data collection details are presented in table 2 .

\begin{tabular}{|c|c|c|c|c|}
\hline Organization & Interviewees & \begin{tabular}{|c} 
Inter \\
view \\
s
\end{tabular} & Interview details & Interview background \\
\hline \multirow[t]{4}{*}{ Client } & Project manager & 2 & $\begin{array}{l}\text { Both interviews lasted for } \\
\text { over an hour and were } \\
\text { face-to-face }\end{array}$ & \multirow{4}{*}{$\begin{array}{l}\text { The client project manager gave detailed } \\
\text { accounts of the project in two interviews at } \\
\text { different stages of the project. Others' } \\
\text { substantiated on work practices and issues } \\
\text { in the project. The external project } \\
\text { manager and projects department provided } \\
\text { background information on client IT } \\
\text { project management. }\end{array}$} \\
\hline & \begin{tabular}{|l|} 
Programmers \\
\end{tabular} & 2 & Questionnaires & \\
\hline & $\begin{array}{l}\text { Project manager } \\
\text { not involved in } \\
\text { this project }\end{array}$ & 1 & $\begin{array}{l}\text { Face-to-face interview } \\
\text { lasting over } 45 \text { minutes }\end{array}$ & \\
\hline & \begin{tabular}{|l|} 
Projects \\
department
\end{tabular} & 1 & \begin{tabular}{|lr} 
Face-to-face over lunch \\
meeting lasting \\
minutes
\end{tabular} & \\
\hline \multirow{2}{*}{$\begin{array}{l}\text { Vendor } 1 \text {-Banking } \\
\text { solutions firm }\end{array}$} & Technical lead & 2 & $\begin{array}{l}\text { Both interviews lasted } \\
\text { over and hour }\end{array}$ & \multirow{6}{*}{$\begin{array}{l}\text { Lead representatives gave detailed } \\
\text { accounts of the project and their } \\
\text { perspectives into the issues. Common } \\
\text { issues arose and allowed for triangulation } \\
\text { of evidence for key findings. Each gave } \\
\text { access to their own team members who } \\
\text { filled out questionnaires. Team members } \\
\text { commented on the nature of relationships } \\
\text { in the team, the camaraderie and the }\end{array}$} \\
\hline & Consultants & 5 & Questionnaires & \\
\hline \multirow[t]{2}{*}{$\begin{array}{l}\text { Vendor 2-Consulting } \\
\text { firm }\end{array}$} & $\begin{array}{l}\text { Lead } \\
\text { representative }\end{array}$ & 1 & $\begin{array}{l}\text { Interview lasted over and } \\
\text { hour }\end{array}$ & \\
\hline & Consultants & 1 & & \\
\hline \multirow[t]{2}{*}{$\begin{array}{l}\text { Vendor 3- Systems } \\
\text { Integrator firm }\end{array}$} & $\begin{array}{l}\text { Lead } \\
\text { representative }\end{array}$ & 1 & & \\
\hline & Consultants & 1 & & \\
\hline
\end{tabular}

Table 2: Case Data details 
This project was the development of a data warehouse and it involved four organizations. The client was a leading bank in Asia and the three vendors; a banking solutions firm, systems integrator and business process consulting firm that were all engaged on a time and material contract ${ }^{1}$. The four organizations were multinational firms with distinct competencies and were represented by an expert each that were all data warehouse experts with 20 plus years of experience. A project team with representatives from all four organizations was set-up and collocated in the client's premises. The project was on for two years at the time of data collection.

\subsection{The knowledge clusters and their roles}

Based on the case data and the definition of knowledge clusters the various knowledge clusters from each organization, their roles and representation to the project team are summarized in table 3. From the client there were four clusters; Client_Management, Client_Users, Client_IM and Client_IT. Client_Users comprised of business users and data analysts and this cluster had to communicate process flows to be incorporated in the data warehouse model and had to use the data model as it was being developed to assess suitability and usability. Client_IT was involved in building the data warehouse along with the vendor organizations. Client_IM was the Information management department which initiated and owned this data warehouse. It coordinated the project and the head of Client_IM was the project manager. Client_Management was involved initially to grant funding for the project after which it followed up with Client_IM after every quarter on the project progress. From the three vendor organizations there was one expert each that was the main coordinator and each brought in a small team for the area of expertise they were hired for. Each vendor organization is therefore considered as a single cluster. The three vendor clusters were; Vendor_Bankingsolutions, Vendor_Systemsintegrator and

\begin{tabular}{|l|l|c|l|l|l|}
\hline \multicolumn{1}{|c|}{ Org } & Clusters & Team & \multicolumn{1}{|c|}{ Role } & \multicolumn{1}{|c|}{ Knowledge Integration behavior } \\
\hline Client & Client_Users & $*$ & $\begin{array}{l}\text { Data analysts \& business users. } \\
\text { Contribute requirements \& use system }\end{array}$ & $\begin{array}{l}\text { Did not see need for the system and } \\
\text { was against it }\end{array}$ \\
\hline & Client_IT & $*$ & $\begin{array}{l}\text { IT dept. Involved in system } \\
\text { development }\end{array}$ & $\begin{array}{l}\text { No prior experience in implementing } \\
\text { data warehouse and resisted system } \\
\text { development method }\end{array}$ \\
\hline $\begin{array}{l}\text { Client_IM } \\
\text { sanking } \\
\text { velutions } \\
\text { vendor }\end{array}$ & $\begin{array}{l}\text { Vendor_Banki } \\
\text { ngSolutions } \\
\text { Systems } \\
\text { integrator } \\
\text { vendor }\end{array}$ & $\begin{array}{l}\text { Vendor_Syste } \\
\text { msintegrator }\end{array}$ & $*$ & $\begin{array}{l}\text { Information management dept. } \\
\text { Managed project and system } \\
\text { development }\end{array}$ & $\begin{array}{l}\text { Did not receive much cooperation from } \\
\text { other clusters }\end{array}$ \\
\hline $\begin{array}{l}\text { Business } \\
\text { process } \\
\text { consulting } \\
\text { vendor }\end{array}$ & $\begin{array}{l}\text { Vendor_Consu } \\
\text { Iting }\end{array}$ & $*$ & $*$ & $\begin{array}{l}\text { Acceded to the project and monitored } \\
\text { troject progress }\end{array}$ & Minimal involvement. \\
\hline
\end{tabular}

Table 3: Knowledge Clusters in the Case

\footnotetext{
${ }^{1}$ Contract where vendors are paid for whatever time and material they put into the project.
} 


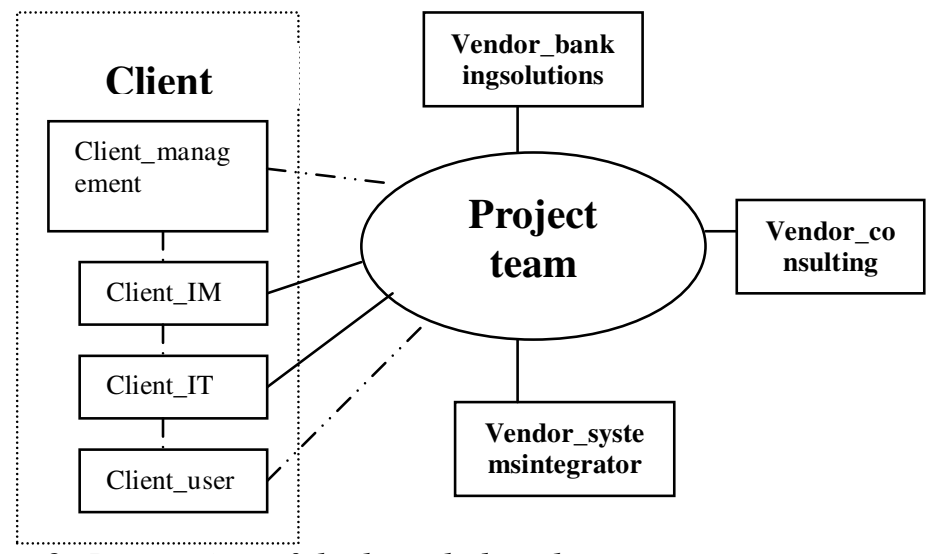

Figure 2: Interaction of the knowledge clusters

The knowledge clusters' interaction in this project is shown in figure 2. Although there was representation of every cluster to the project team, some of the links were not effective. The dotted lines indicate ineffective links/ impeded knowledge flow from those clusters to the project team.

The client had several hierarchies and knowledge flow between the hierarchies was ineffective. Client_IM was the project manager for the project and this cluster had little clout on the other clusters in terms of getting their buy-in for the project and enthusing their involvement and participation. Client_User and Client_IT did not perceive a need for the system which meant lack of their involvement and hence knowledge contribution for knowledge integration. Client_IM said: "Client_Management agreed to the project, but the user departments were only passively involved in the project. Client_Management also never followed up with them." Due to the lack of perception of strategic benefit, Client_Users did not use the system when it was ready thus affecting system assimilation for knowledge integration as well. Client_Management acceded to the project but was seldom involved in the project activities had very little communication and interaction with the other clusters so its commitment was not visible to the other clusters. Restructuring in the client further disrupted knowledge from some clusters since key people left. Communication with the vendor clusters was simpler since each had a lead representative who was the single point of contact to that cluster. The project team was collocated in the client's office which did help in technical team communication between all those who were actively involved.

Although representatives were assigned from Client_User to streamline communication between the vendors and Client_Users, they seldom participated in the project activities and hence their knowledge contribution to the project was affected. Effectively it was only Client_IM that served as a link from the client to the project team. Vendor_Consulting said: "Although each of the vendors was assigned a user representative, they never participated in the project and were hardly present for meetings and so it was very difficult to get the knowledge needed from users." Client_IT was also in the project team to assist in building the data warehouse but during system development it had issues in accepting the development methodology proposed by the vendors despite having a lot of experience with IT projects. The vendor's attributed this to Client_IT's lack of experience in building data warehouse which required a methodology different from standard systems development life cycle followed for normal IT applications. This friction between impeded knowledge integration since more time was spent in convincing each other. One of the vendors said: "Client_IT's lack of experience in data warehouse meant lot of time convincing them on the development methodology and necessary process changes." 
If knowledge integration was affected due to the lack of common knowledge in terms of development methodology between Client_IT and the vendors, knowledge integration was also affected due to too much common knowledge. The lead representatives of all the three vendor clusters had over 20 years of data warehouse experience and were all equally passionate about data and this project. Though hired for expertise in a particular area the overlap in their knowledge bases made technical knowledge communication between them easier but also led to frequent clashes on the best way of doing things. Client_IM had to frequently resolve such clashes and admitted: "We needed all of their expertise, but unfortunately they came from different organizations and there was too much overlap of knowledge. There should be just enough common knowledge to have a shared understanding of things, but not overlapping expertise." Knowledge integration was affected since more time was spent resolving issues, there was lack of knowledge dependency between the clusters, lack of appreciation for specialized knowledge base of other clusters and hence lack of harmony in the process.

Client_management intended to have the data warehouse within a certain time and budget but the vendor clusters were hired on a time and material contract that provided little motivation for them to speed-up the project when delays were imminent. Vendor_bankingsolution said: "Our contract does not state that we have to complete the project within the time frame." Even when there were process changes in the client organization which meant delays Vendor_Systemsintegrator was unfazed: "It is alright for me if they have changes, the customer is the king, We are hired on time and material basis, so any delays does not affect us since we get paid for every man-hour we put in." Knowledge integration suffered since the time and material contract on which the vendor clusters were engaged did not ensure a concerted effort on part of all clusters to work towards achieving effective knowledge integration in terms of finishing the project on time. This is in addition to ineffective knowledge integration due the lack of knowledge from some clusters reaching the project team.

\section{DISCUSSION AND FINDINGS}

In recent years organizational researchers have tried to examine multilevel theoretical perspectives for concepts such as creativity, learning and system usage (e.g. Burton-Jones and Gallivan 2007). Many knowledge management scholars (e.g. Merali 2001) also suggest the importance of considering knowledge management approaches across different organizational levels and also acknowledge (Nonaka and Takeuchi 1995) the difficulties in doing so. This is something evidenced in this study as well and as mentioned in the methodology section, the use and change of theory and analysis was subject to the data and preliminary analysis. Initial analysis for this study was conducted at the organizational level but many issues could not be explained very well. For instance, although a typical client vendor relation, where in one client hired three vendors for a project and motivation for all parties should be obvious, this was not witnessed and it could not be explained at the organizational level. The problem was the various clusters within the client organization had different perceptions towards the project. A cluster level analysis was then used and that could explain the behavior of the different groups; Client_User and Client_IT, toward knowledge integration. Based on this understanding of knowledge cluster and the case, inter-organizational knowledge integration is explained as a process that involves complementary specialized knowledge clusters interacting within certain structures and influenced by the clusters' perception towards the project.

For the project, complementary specialized knowledge bases are identified from within the organization (e.g. users, IT departments) and outside the organization (the vendors). This is an important process considering organizations often have problems identifying the content, location, and use of the knowledge for software engineering (Inkpen and Tsang 2005). This is also consistent with the importance accorded to partner selection in alliances (Dodgson 1992) considering the length of time needed to build effective communication paths between organizations and the nature of knowledge to be shared. The concern is alike in long term collaborative IS projects. The case shows that in identifying the knowledge clusters, organizations base their selection in trying to find complementary knowledge bases that are needed for the project and make some effort to facilitate 
exchange between the clusters by building a common knowledge base through social activities and team collocation, for instance. Common knowledge is the common understanding of a subject area (Demsetz 1991) that enables easier transfer, sharing or integration of knowledge (Alavi and Tiwana 2002).Although the three vendors were selected for their specialized knowledge in different domains, the representatives were all data warehouse experts and the common knowledge they shared did make knowledge exchange easier but also led to conflicts. Too much common knowledge is shown to be impeding for knowledge integration as much time was spent in resolving conflicts. The specialized knowledge bases of the vendors were not sufficiently complementary and hence dependency between the clusters was lacking. The lack of common knowledge between the vendor clusters and Client_IT in terms of system development methodology and between the vendor clusters and Client_Users in terms of understanding of data warehouse benefits also hampered knowledge integration. The case therefore suggests that when specialized knowledge of the clusters is sufficiently complementary there is a dependency between the clusters and more harmonious interaction for knowledge integration while at the same time common knowledge between the clusters enables a shared understanding of issues for knowledge integration but too much redundancy can also be ineffective. This emphasis on a balance between specialized and common knowledge is the contribution of this finding to existing literature.

The knowledge clusters interact within their own organizational structures (clusters from within an organization) as well as within the project structure (project team) and that serves as means through which their knowledge reaches the project. Gulati(1995) affirms there are usually no preexisting reporting relationships in an alliance or systems that serve as natural conduits for information and therefore structures have to be created for that purpose. This is typically the case in interorganizational IS projects where the project team consists of members from different clusters across organizations and a reporting structure can be cross organizational and is created for the duration of the project. In the case, clusters within the client were all represented to the project team but the representatives were not actively involved in project activities (refer figure 2) and hence access to their knowledge was inefficient. Infrequent involvement of the Client_Management and Client_Users, lack of ties between them and Client_IM and restructuring in the client hampered their knowledge flow to the project. The structure was present but was ineffective in providing access to certain clusters' knowledge thus blocking required knowledge to the project. The case shows that knowledge flows, enabled by the structures, should exist within the various knowledge clusters involved in the project and within the core project team. The main idea of the structures should be to provide a channel for knowledge from all the involved clusters to reach the project. Prior literature has stressed on communication channels for knowledge flows (e.g. Ravasi and Verona 2001). Grant (1996) argues that structures that provide organizations with a comparative advantage in managing the various knowledge processes are a critical strategic variable while Huang and Newell (2003) suggest that efficient collaboration in a team requires the explicit definition of the communication channels desired within the team. The distinction on the findings in this paper is the observation that when the structure allows effective communication between all the knowledge clusters and not just between organizations and simultaneously between the clusters and the core project team knowledge integration better facilitated.

The involvement of the knowledge clusters in the knowledge integration process is contingent on their motivation for the project determined by factors such as; their need for the system, effort and cost incurred, value for their business and contractual terms. Lack of motivation of the knowledge clusters affects their knowledge integration behavior in terms of lack of effort, involvement and knowledge contribution to the project. In this case, Client_Management intended to have the system within a certain time and budget but the vendors were hired on a time and material contract that provided them little incentive to hasten the project. Their goals were not synchronous and that led to ineffective knowledge integration due to lack of concerted effort on the part of all clusters to expedite the project as Client_IM confirmed: "The distinct KPIs of all four organizations affected the project." Further, the lack of perception of benefits form the data warehouse affected Client_Users effort in contributing and assimilating knowledge for the project. Motivation in different forms has been identified as an influencing factor for several knowledge processes (e.g. Kankanhalli et al 2005) but the focus was on 
individuals or organizations. The contributions of this finding is the emphasis of motivation at the level of knowledge clusters as against at the individual/organizational level. Project benefits are usually mutual in a client-vendor relationship (client needs system; vendor needs business) but concerted effort towards knowledge integration (Huang and Newell 2003) is not always present as shown in the case because of differing perceptions among the knowledge clusters. The study also finds that contractual terms used for legal protection and as means to control behavior of partners (e.g. Choudhury and Sabherwal 2003) can help synchronize goals in the project towards effective knowledge integration.

The above discussion and understanding of inter-organizational knowledge integration are summed up in table 3 below as three findings.

\begin{tabular}{|l|l|l|}
\hline Findings & Contributions & Implications \\
\hline $\begin{array}{l}\text { Sufficiently complementary } \\
\text { knowledge bases of the clusters } \\
\text { ensure dependency and some } \\
\text { common knowledge between them } \\
\text { facilitates knowledge exchange for } \\
\text { effective knowledge integration. }\end{array}$ & $\begin{array}{l}\text {-Emphasizing cluster level } \\
\text { complementarities rather than } \\
\text { organizational level } \\
\text {-Emphasis on balance between } \\
\text { complementary and common } \\
\text { knowledge between clusters }\end{array}$ & $\begin{array}{l}\text {-Identify clusters such that } \\
\text { there is complementarity/ } \\
\text { dependency between them } \\
\text {-Measures to build/develop } \\
\text { common knowledge }\end{array}$ \\
\hline $\begin{array}{l}\text { Structures instituted provide a } \\
\text { platform for knowledge clusters to } \\
\text { interact and a channel for their } \\
\text { knowledge to reach the project. }\end{array}$ & $\begin{array}{l}\text {-Knowledge based objective for } \\
\text { structures } \\
\text {-Cluster representation } \\
\text { organizational representation }\end{array}$ & $\begin{array}{l}\text {-Design structures to } \\
\text { represent all clusters and } \\
\text { provide channels } \\
\text { knowledge flows. } \\
\text { for }\end{array}$ \\
\hline $\begin{array}{l}\text { Knowledge integration is effective } \\
\text { when there is concerted effort on } \\
\text { part of the clusters toward the } \\
\text { project. }\end{array}$ & $\begin{array}{l}\text {-Knowledge cluster motivation stable } \\
\text {-Importance of concerted effort }\end{array}$ & $\begin{array}{l}\text {-Measures/incentives such as } \\
\text { contract need to be instituted/ } \\
\text { phrased accordingly }\end{array}$ \\
\hline
\end{tabular}

Table 3: Findings for effective knowledge integration

\section{IMPLICATIONS AND CONCLUSION}

One of the key contributions of this study is the concept of knowledge cluster (figure 1) that affords conceptualization of the complex phenomenon of inter-organizational knowledge integration by abstracting the multiple levels (individual, group, organizational and inter-organizational) and their interactions in an inter-organizational context. The concept of knowledge clusters allows escalating issues at each level to a knowledge level, thus making it easier to comprehend the issues from a unified perspective. Knowledge clusters stem from and exist within the organizational structure thus encapsulating the inter-organizational dynamics, organizational and inter-departmental dynamics, as well as the dynamics of the individuals within the cluster. The concept is also a contribution to multilevel research and it addresses a call for such studies by Burton-Jones and Gallivan(2007). In a setting such as collaborative project involving knowledge integration it is essential to understand the correct behavior of organizations within the collaborative set-up. As the case shows it is at times hard to understand the behavior of the organization as such since the multiple clusters within behave differently so when grouped as clusters this behavior and hence possible solutions are clearer. This concept is of significance to knowledge integration literature in various inter-organizational contexts like joint ventures and alliances as well as to any knowledge intensive contexts like R\&D and new product development. The understanding of inter-organizational knowledge integration through processes involving the knowledge clusters contribute to the underlying inter-organizational knowledge integration theory and go beyond those identified by earlier studies and restricted to intraorganizational contexts. Although the processes identified by Huang et al(2001) can be also be applicable to this context, they do not incorporate multiple dimensions critical to the 
context(structural, motivational and cognitive) and aspects critical to the inter-organizational context (synchronizing goals of all clusters across the organizations).

The challenge in managing IS/IT projects, especially those involving multiple organizations, is well known and acknowledged. This paper provides a knowledge integration perspective to address the knowledge related challenges that traditional project management strategies did not address. This is essential since the goal of the project is to integrate the various knowledge bases. Based on this approach project management strategies can be developed to manage the knowledge clusters within the project environment to influence their knowledge integration behavior for the goal of the project. Specifically (column 3 in table 3), this study suggests that for effective knowledge integration, knowledge clusters for the project should be identified keeping in mind the complementary nature of their knowledge bases and providing mechanisms for fostering common knowledge between them. Secondly, all clusters buy-in for the project should be obtained so as to ensure their concerted effort towards the project. Although this finding is not new, the implication is on focusing on the knowledge clusters rather than departments/organizations/individuals since it is the knowledge of the clusters that has been identified as essential for the project. Lastly, structures instituted should enable interaction between the clusters and effective knowledge flows.

This study was conducted in an Asian country and there was an element of conservatism shown by the interviewees in revealing data that may have affected some of the insights. To overcome this limitation, multiple people were interviewed on the same subject. The organizations also hesitated to share too many project related documents and to make up for this multiple people were interviewed to get oral confirmation of the data. It must also be noted that this study has the inherent limitations of a case study in terms of it being very context specific. The goal of this paper is therefore not to make generalizations applicable to all settings, but to be able to contribute to the underlying knowledge integration theory. The concept of knowledge clusters introduced in this study is novel and should be examined more rigorously especially their evolution and behaviour over the life cycle of the project and suitable structures for their interaction in different client-vendor settings. Another interesting aspect would be to explore their dynamics in- specific inter-organizational arrangements (one client vs. one vendor, multi client vs. one vendor). The observations in this study are based on a single case and need to be further researched through questionnaires or more detailed case studies.

\section{References}

Alavi, M. and Tiwana, A. (2002). Knowledge Integration in Virtual Teams: The Potential Role of KMS. Journal of the American Society for Information Science and Technology, 53(12), pp. 1029-1037.

Bhandar, M., Pan, S.L., and Tan, B.(2007), Towards Understanding the Roles of Social Capital in Knowledge Integration: A Case Study of a Collaborative IS Project. Journal of the American Society for Information Science and Technology, 58(2), pp.263-274.

Burton-Jones, A. and Gallivan, M.J.(2007). Towards a Deeper Understanding of System Usage in Organizations: A Multilevel Perspective. MIS Quarterly (31:4), pp. 657-679. Awarded the MISQ Best Paper Award, 2007.

Carlile, P. and Rebentisch, E., (2003), Into the black box: The Knowledge Transformation Cycle, Management Science, 49, 1180-1195.

Choudhury, V. and Sabherwal, R. (2003), Portfolios of Control in Outsourced Software development Projects." Information Systems Research., 14(3), pp. 291-314.

Demsetz, H. (1991). The Theory of the Organization Revisited, In O.E. Williamson and S. Winter (Eds), The Nature of the Organization, New York: Oxford University press, pp. 159-178.

Denzin N. K. and Lincoln, Y. S. (Editors). Handbook of Qualitative Research, Sage Publications, 1994.

Dodgson, M. (1992). Organizational Learning: A Review of Some Literatures. Organization Studies, 14(3), pp. 375-394.

Faraj, S. and Sproull, L. (2000). Coordinating Expertise In Software Development Teams. Management Science 46(12).

Grant, R. (1996). Prospering in dynamically-competitive environments: Organizational capacity as Knowledge Integration. Organization Science, 7(4), 1996, pp. 375-387. 
Gulati ,R.,(1995), Social Structure and Alliance Formation Patterns: A Longitudinal Analysis, Administrative Science Quarterly, 40, 619-652

Huang J. C., Newell S. and Pan S.L. (2001), The Process of Global Knowledge Integration: A Case Study of a Multinational Investment Bank's Y2K program. European Journal of Information Systems, 10(3), pp. 161174.

Huang, J.C. and Newell, S. (2003), Knowledge integration processes an dynamics within the context of crossfunctional projects, International Journal of Project Management, 21, pp. 167-176.

Inkpen, A.C. and Tsang, E.W.K. (2005), Social Capital, Networks and Knowledge Transfer. Academy of Management Review, 30(1), pp. 146-165.

Kankanhalli, A., Tan, B.C.Y. and Wei, K.K. (2005). Contributing Knowledge to Electronic Knowledge Repositories: An Empirical Investigation. MIS Quarterly, 29(1), pp. 113-144.

Levina, N. (2005). Collaborating on Multiparty Information Systems Development Projects: A Collective Reflection-in-Action View. Information Systems Research, 16(2), pp. 109-130

Merali, Y. (2001). Leveraging Capabilities: A Cognitive Congruence Framework, in Knowledge Management and Organizational Competence. Ed. Sanchez, R., Oxford University Press, New York.

Myers, M. D. (1997). Qualitative Research in Information Systems. MIS Quarterly, 21(2), pp. 241-242.

Nonaka, I.(1994). A dynamic theory of organizational knowledge creation. Organization Science, 5 (1), pp. 1437.

Nonaka, I. and Takeuchi, H. (1995). The Knowledge-Creating Company, Oxford University Press, New York.

Okhyusen, G. A. and Eisenhardt K. M.(2002). Integrating knowledge in groups, Organization Science, 13(4), pp. 370-386.

Pan, S-L., Newell, S., Huang, J. C. and Cheung, A. W. K. (2001). Knowledge Integration as a Key Problem in an ERP Implementation. Twenty-second International Conference on Information Systems, New Orleans, USA, pp. 321- 328 .

Pan, S. L., Newell, S., Huang, J.C.M and Galliers, R. (2007). Overcoming Knowledge Management Challenges During ERP Implementation: The Need to Share and Integrate Different Types of Knowledge. Journal of the American Society for Information Science and Technology, 58(3), pp. 404-419

Pisano, P.G. (1994). Knowledge Integration and the Locus of Learning: An empirical analysis of process development. Strategic Management Journal. 15(Special issue-Competitive Organizational Behavior), pp. 85-100.

Polanyi M. (1966). The tacit dimension, Garden City, N.Y. Doubleday.

Ravasi, D. and Verona, G. (2001). Organizing the Process of Knowledge Integration: The Benefits of Structural Ambiguity. Scandinavian Journal of Management, pp. 17 41-61.

Simatupang, T., Wright, A., Sridharan, R. (2002). The Knowledge of Coordination for Supply Chain Integration. Business Process Management Journal, 8(3), pp. 289-308.

Spender, J. (1996). Making Knowledge the basis of a Dynamic theory of the organization. Strategic Management Journal, 17(Winter Special Issue), pp. 45-62.

Stake, R. E.(1994). Case Studies, In, Denzin N. K., and Lincoln, Y. S. (Editors). Handbook of Qualitative Research, Sage Publications, pp. 236-247.

Strauss and J. Corbin. (1990). Basics of qualitative research: grounded theory procedures and techniques. Sage, London.

Tsoukas, H. (1996). The firm as a distributed knowledge system: a constructionist approach. Strategic Management Journal, 17 (Winter, Special Issue), pp. 11-25.

Van den Bosch, F.A.J., Volberda, H.W. and Boer, M.(1999). Coevolution of Firm Absorptive Capacity and Knowledge Environment: Organizational Forms and Combinative Capabilities. Organization Science, 10(5), pp. 551-568.

Walsham, G. (1995). Interpretive Case Studies in IS Research: Nature and Method. European Journal of Information Systems, 4(2), pp. 74-81.

Walsham, G. (2006). Doing Interpretive Research: Nature and Method. European Journal of Information systems, 15, pp. 320-330.

Walz, D., Elam, J. and Curtis,.B. (1993). Inside a Software design team: knowledge acquisition, sharing and integration. Communications of the ACM, 36(10), pp. 63-77.

Yayavaram, Sai and Ahuja, Gautam. (2008). Decomposability in knowledge structures and its impact on the usefulness of inventions and knowledge base malleability. Administrative Science quarterly, 53. pp.333-362.

Yin, R.K. (2003). Case Study Research: Design and Methods. Sage Publications, Beverly Hills, CA. 3rd ed. 